\title{
Editorial
}

\section{Impactos sociales y económicos de la pandemia de la COVID-19 en Latinoamérica}

http://doi.org/10.14718/revfinanzpolitecon.v12.n2.2020.3730

\section{Joan Miguel Tejedor-Estupiñán*}

Durante su historia, la humanidad ha tenido que afrontar, investigar y superar innumerables enfermedades infecciosas, muchas de ellas con alcances de epidemia y de pandemia. Existen datos de múltiples epidemias de influenza, como la que se expandió por Mesopotamia y Asia meridional hacia el 1200 a. C., hasta la pandemia de la gripe de influenza entre 1889 y 1890 . También diversas epidemias de pestes bubónicas producidas por el patógeno Yersinia pestis, como la plaga de Justiniano (541-542), que se originó en el Imperio Romano y se extendió en Europa y Asia del Este; la Peste Negra (1346-1356), la Plaga Rusa (1770-1772), entre otras epidemias de este patógeno que se expandieron por diversas ciudades de Europa, África y Norte América durante los siglos XVI y XVII. Se han registrado epidemias de viruela como las de Japón (735-737) y Tenochtitlán (1519-1520); la epidemia de salmonela de Cocolitzli (1545-1548) en el Virreinato de Nueva España; la fiebre amarilla (1793-1794), que se expandió por Filadelfia; las pandemias de cólera como la de India (1817-1824), Asia, Europa y Norte América (1852-1860); la pandemia conocida como gripe española (1918-1920) y la gripa porcina de (2009-2010), ambas producidas por el patógeno influenza A-H1N1; la pandemia del síndrome de inmunodeficiencia adquirida (SIDA), producida por el VIH (1981). Finalmente, durante lo corrido del siglo XX, hemos presenciado algunas nuevas epidemias como la del ébola (2014-2016), el dengue (2002-2001), el zika (2015-2016) y la gripa COVID-19, producida por el patógeno SARS-CoV-2 (2019-2020)². Y hay muchas otras más documentadas por los historiadores y epidemiólogos de todo el mundo (Serrano-Cumplido et al., 2020).

1 Ph.D. (C) en Economía, Magíster en Derechos Humanos y Economista. Editor de la Revista Finanzas y Política Económica de la Universidad Católica de Colombia. Dirección de correspondencia: Facultad de Economía, Universidad Católica de Colombia, Carrera 13 n. ${ }^{\circ} 47-49$ (Bogotá, Colombia). Correo electrónico: jmtejedor@ucatolica.edu.co. (D Orcid: https://orcid.org/0000-0002-2346-3222

2 Para conocer más información sobre el origen de la gripa COVID-19, ver el artículo de Andersen et al. (2020): "The proximal origin of SARS-CoV-2". 
Los patógenos que más han acumulado muertes durante la historia son la Viruela (ya erradicada), descubierta en 1796, que dejó más de 300 millones de víctimas humanas; el Morbillivirus (sarampión), que desde su descubrimiento en 1954 ha dejado más de 200 millones de víctimas; el Yersina pestis, descubierto en 1854, que ha acumulado más de 150 millones de muertes; el virus de la hepatitis $B$, con más de 60 millones de muertes; el virus de la influenza A-H1N1, con más de 50 millones; el VIH, con más de 35 millones; y actualmente el SARS CoV-2 (Gripa COVID-19), con más de 1 millón de muertes hasta julio de 2020 (Johns Hopkins University \& Medicine, 2020).

En enero de 2020, la Organización Mundial de la Salud (OMS) evaluaba el riesgo real de la epidemia, por lo cual recomendó en todo el ámbito mundial adoptar medidas previamente implementadas para la gripe y las infecciones respiratorias graves, sin considerar necesario limitar los viajes internacionales. Ante el aumento de la epidemia a nivel internacional, el 11 de marzo de 2020 esta organización decretó el estado de pandemia, recomendando a los países la implementación de medidas inmediatas y hacia futuro, teniendo en cuenta que, a pesar de la historia de las pandemias, no estábamos preparados. De manera inmediata se recomendó: a) estrategias para detectar, aislar, tomar test, tratar cada caso y trazar sus contactos; b) adecuar los hospitales; c) proteger y entrenar a los trabajadores de la salud; d) comunicar a la población los riesgos y cómo las personas se pueden autocuidar; e) diseñar estrategias para reducir la transmisión; f) cuidarnos y cuidar a los demás; y g) aprender e innovar. De igual modo, se propone hacia futuro: a) promover el aprendizaje y la innovación; b) detectar, proteger y tratar; c) dotar, adecuar y preparar los hospitales; d) preparar, educar y entrenar a la sociedad y estar listos; e) dotar, adecuar y preparar a la atención primaria; y f) proteger y entrenar a los trabajadores de la salud (Serrano-Cumplido et al., 2020).

Para facilitar la difusión y el intercambio de experiencias y la gestión de la pandemia en los países de la región, la Comisión Económica para América Latina y el Caribe (CEPAL) creó el Observatorio COVID-19 en América Latina y el Caribe, una herramienta que recopila información sobre las acciones implementadas por los países de la región para enfrentar la pandemia, la cual está desagregada por los siguientes tipos de medidas: restricciones de movimientos, salud, economía, empleo, protección social, educación y próximamente género (CEPAL, 2020b). Con relación a las restricciones a los movimientos, las principales medidas tomadas por los países de la región fueron las relacionadas con restricciones o prohibiciones a la entrada de viajeros extranjeros, cierres y controles fronterizos, restricción o cierre de lugares públicos y reuniones masivas (94\%, 77\%, 97\% de los países, respectivamente); con respecto a la salud, las actividades de emergencia (87\%) y las 
cuarentenas obligatorias a extranjeros y viajeros (87\%) contrastaron con el porcentaje de países que invirtieron en hospitales (26\%); las estrategias económicas más implementadas por los países se han relacionado con la política de empresas $(71 \%)$, la restricción de la actividad económica (77\%) y la política fiscal (68\%), en contraste con los estímulos económicos (32\%) y el alivio de la deuda y suspensión de pagos de crédito (13\%); con relación al empleo, mientras el 84\% de los países tomaron medidas de protección del empleo, solo $26 \%$ tomaron medidas relacionadas con permisos de trabajo remunerado y $29 \%$ con relación a la prohibición de despido del trabajo; respecto a la protección social, las medidas preferidas por los países de la región fueron las transferencias en efectivo (55\% de los países), en contraste con las transferencias de alimentos o en especie (16\%) y la garantía de servicios básicos (16\%); finalmente, con respecto a la educación, el 100\% de los países decretaron la suspensión de clases, el 71\% está implementando instrumentos para mantener educación en línea o a distancia, y solo un $16 \%$ de los países mantienen programas de alimentación escolar (CEPAL, 2020b).

Las proyecciones de la CEPAL para la región con respecto al crecimiento, la desocupación, la pobreza y la desigualdad predicen una caída promedio del PIB del 9,1\% en 2020, con disminuciones del 9,4\% en América del Sur, el 8,4\% en Centroamérica y México, y el 7,9\% en el Caribe. Se espera que la tasa de desocupación regional se ubique alrededor del 13,5\% al cierre de 2020; la desocupación afectará a más de 44,1 millones de personas, lo que representa un aumento cercano a 18 millones con respecto al nivel de 2019; se proyecta que la pobreza afectará a 45,4 millones de personas en 2020 , con lo que el total de personas en situación de pobreza pasaría de 185,5 millones en 2019 a 230,9 millones en 2020 , cifra que representa el $37,3 \%$ de la población latinoamericana; dentro de este grupo, la pobreza extrema afectaría a otras 28,5 millones de personas, pasando de 67,7 millones de personas en 2019 a 96,2 millones de personas en 2020, cifra que equivale al $15,5 \%$ del total de la población; se proyecta además que el índice de Gini se incrementaría entre un $1 \%$ y un $8 \%$ en los 17 países analizados, aumentando por tanto la desigualdad en la distribución del ingreso en los países de la región (CEPAL, 2020a).

Una de las medidas más cuestionadas durante lo corrido de la pandemia fue el confinamiento estricto (muy pocos países extendieron hasta agosto, como Ecuador y Colombia). Algunos científicos como Michael Levitt (Premio Nobel de Química en 2013) alertaron que los impactos de los confinamientos estrictos (cerrar las escuelas, frenar los trabajos, parar las tiendas, cerrar todo) podrían salvar unas vidas en el corto plazo, pero al afectar la economía sería una estrategia peligrosa. El nobel afirma que en unos pocos países de Europa donde se ha implementado un confinamiento más flexible, el número de muertes no ha 
sido más alto en comparación con un país con confinamiento más estricto, como Suecia y Reino Unido, donde las muertes por millón de habitantes son muy similares. Finalmente, afirma que aunque aún no se saben los daños acumulados causados por el confinamiento a la economía mundial y a la sociedad, teme que muchos países que están saliendo del confinamiento vean un aumento grande en la tasa de trastornos mentales, de suicidios y de violencia doméstica, e incluso un incremento en los divorcios (Stringham, 2020). A estos efectos debemos sumar el aumento de la corrupción en Latinoamérica, la cual en sí misma es una pandemia que se expande por las instituciones, corporaciones e individuos, y que tiene sus propios impactos económicos y sociales (Kitroeff y Taj, 2020). Igual sucede con la violencia generada por bandas criminales y narcotraficantes, como en el caso de Colombia, donde en lo corrido del 2020 los grupos al margen de la ley han perpetrado más de 33 masacres, asesinando a más de 100 personas (que incluyen líderes sociales, estudiantes, indígenas, afrodescendientes o desmovilizados de las guerrillas de las FARC) (Turkewitz, 2020).

Después de cinco meses de haberse decretado la pandemia por la OMS, el organismo contabiliza 29 proyectos de vacuna que ya están en la etapa de estudio clínico. Hasta el 13 de agosto, solo seis se ubicaban en la fase 3, la más avanzada, lo cual implica la experimentación en grandes grupos de personas: AstraZeneca-Oxford (Estados Unidos), Sinovac (China), Sinopharm-Instituto de Productos Biológicos de Wuhan (China), SinopharmInstituto de Productos de Pekín (China), Moderna-NIAID (Inglaterra) y BioNTech-Fosun Pharma-Pfizer (Estados Unidos). Los gobiernos latinoamericanos están estableciendo acuerdos con diversos proyectos de otros países, como en el caso de México y Argentina con AstraZeneca-Oxford, en su búsqueda de producir y distribuir la vacuna para todos los países de la región. Por otro lado, Rusia ya aprobó su vacuna llamada Sputnik V, independientemente de la OMS, asegurando que producirá estas vacunas en Cuba y Brasil (Brooks, 2020). Mientras tanto, las medidas de distanciamiento personal y social se espera duren hasta 2022.

Los impactos económicos y sociales derivados del SARS-CoV 2 han dejado al descubierto la incapacidad histórica de los países y del ser humano para aprender de las epidemias y pandemias del pasado. Las medidas de emergencia tomadas por todos los países en el mundo evidenciaron la distribución desigual de los recursos, la falta de inversión en infraestructura, los protocolos inadecuados para enfrentar estos eventos, así como los impactos económicos y sociales derivados, en particular en Latinoamérica, donde además se observaron sistemas de protección social y salud insuficientes, escenarios 
de corrupción con los recursos de la pandemia, devastación de la selva y resurgimiento del narcotráfico y la violencia en algunos países. En este punto es necesario recordar los movimientos sociales que resurgen luego de los confinamientos estrictos y que antes de la pandemia caracterizaron el año 2019, tales como el de los chalecos amarillos en Francia (que se extendió por varios países de Europa durante ese año), las protestas en Hong Kong, las marchas de Black Lives Matter en Estados Unidos, y las protestas en América Latina, desde Chile, Bolivia, Brasil, Ecuador y Colombia, donde los manifestantes han venido advirtiendo, entre otros aspectos, de las fallas en los sistemas democráticos, que conllevan las insuficiencias institucionales y financieras descritas. Sin duda alguna, el confinamiento obligatorio dejó aspectos positivos para el medioambiente, en especial para el aire, el agua y el suelo, al reducir la actividad industrial a nivel global; en algunas ciudades se dieron avistamientos de especies animales, poco frecuentes en épocas de actividad humana normal; la naturaleza tomó un descanso de la actividad económica; muchas empresas e instituciones aprendieron de las ventajas del modelo de ventas por medio de internet y adaptaron sus modelos de servicios y ventas a un sistema en línea. En este último contexto, la protección y recolección de datos por medio de internet, a través de dispositivos móviles y aplicaciones, vuelve al centro del debate en un mundo donde el derecho a la privacidad, al acceso a información verídica y el derecho a la libertad de expresión están siendo vulnerados tanto por los criminales cibernéticos, como por los mismos gobiernos, organismos de seguridad y empresas privadas, que monopolizan la información y el big data para sus fines individuales, que en algunos casos están por encima del interés público.

De acuerdo con lo anterior, desde el Comité Editorial de la Revista Finanzas y Política Económica queremos enviar un saludo de solidaridad a todo el equipo editorial, a los lectores, evaluadores y autores en estas épocas de pandemia, esperando que esta experiencia acumulada nos deje las enseñanzas sociales, económicas, políticas y culturales que encaminen a la humanidad por un sendero de desarrollo integral, equitativo y sostenible. Queremos agradecer en particular a los investigadores de diferentes instituciones de investigación y educación superior de países como México, Chile, Ecuador y Colombia, quienes, a pesar de los tiempos inciertos que vivimos, contribuyeron con sus aportes para conformar la presente edición y aportar con los resultados de sus investigaciones a las áreas relacionadas con las finanzas y la política económica. 
Editorial

\section{REFERENCIAS}

1. Andersen, K. G., Rambaut, A., Lipkin, W. I., Holmes, E. C. y Garry, R. F. (2020). The proximal origin of SARS-CoV-2. Nature Medicine, 26(4), 450-452. https://doi.org/10.1038/s41591-020-0820-9

2. Brooks, D. (2020). Las vacunas para el COVID-19 que se están desarrollando en América Latina (además de la de AstraZeneca-Oxford). https://www.bbc.com/mundo/noticias-america -latina-53774309

3. Comisión Económica para América Latina y el Caribe (CEPAL) (2020a). Enfrentar los efectos cada vez mayores del COVID-19 para una reactivación con igualdad: nuevas proyecciones. https://www. cepal.org/es/publicaciones/45782-enfrentar-efectos-cada-vez-mayores-covid-19-reactivacionigualdad-nuevas

4. Comisión Económica para América Latina y el Caribe (CEPAL) (2020b). Informe sobre el impacto económico en América Latina y el Caribe de la enfermedad por coronavirus (COVID-19). https:// www.cepal.org/es/publicaciones/45602-informe-impacto-economico-america-latina-caribe-laenfermedad-coronavirus-covid

5. Johns Hopkins University \& Medicine (2020). COVID-19 Dashboard by the Center for Systems Science and Engineering at Johns Hopkins University. https://coronavirus.jhu.edu/map.html

6. Kitroeff, N. y Taj, M. (2020). Los villanos del virus en Latinoamérica: especuladores de equipos de protección y funcionarios corruptos. https://www.nytimes.com/es/2020/06/20/espanol/americalatina/corrupcion-coronavirus-latinoamerica.html

7. Serrano-Cumplido, A., Antón-Eguía Ortega, P. B., Ruiz García, A., Olmo Quintana, V., Segura Fragoso, A., Barquilla Garcia, A. y Morán Bayón, A. (2020). COVID-19. La historia se repite y seguimos tropezando con la misma piedra. Semergen, 46(1), 48-54. https://doi.org/10.1016/j. semerg.2020.06.008

8. Stringham, E. P. (2020). Nobel Laureate Michael Levitt on the lockdowns: "I think it is a huge mistake". https://www.aier.org/article/nobel-laureate-michael-levitt-on-the-lockdowns -i-think-it-is-a-huge-mistake/

9. Turkewitz, J. (2020). Aumentan las masacres en Colombia a pesar del Acuerdo de Paz. https:// www.nytimes.com/es/2020/09/13/espanol/america-latina/colombia-protestas-masacres.html 